\title{
PENGEMBANGAN WEARABLE ROBOTIC ARM INPUT DAN VIRTUAL INSTRUMENT UNTUK PENGENDALIAN DAN PEMANTAUAN LENGAN ROBOT
}

\author{
I.M.W. Ekaputra ${ }^{1}$, Joga Dharma Setiawan², \\ 1Jurusan Teknik Mesin, Fakultas Sains dan Teknologi, Universitas Sanata Dharma \\ Paingan, Maguwoharjo, Depok, Sleman-Yogyakarta 55282, Telp. +62274 883037. \\ 2Jurusan Teknik Mesin, Fakultas Teknik, Universitas Diponegoro \\ JI. Prof. Sudharto, SH., Tembalang-Semarang 50275, Telp. +62247460059 \\ E-mail: made@usd.ac.id
}

\begin{abstract}
This paper investigate the integration of wearable robotic arm input (WRAl) with virtual instrument (VI) for controlling and monitoring the manipulator. The WRAI was designed by following the contours of human arms and equipped with five potentiometers as the sensor. The sensors were placed properly on WRAl by considering the ergonomic aspect. Each sensor on WRAI actuate each joint on the manipulator. The manipulator has five degrees of freedom (DOF) which consists of five revolute joints. For monitoring process, control panel of VI was created suitably by LabVIEW, and its block diagram was mainly programmed by following the forward kinematics approach. The VI obtains the input signal from the rotation of potentiometer on WRAI, and then transmitted to the receiver on manipulator to actuate the joints. By monitoring the control panel, the user can observe each angle joint on manipulator and also the position and orientation of end effector. The test results show the WRAI performs good controllability and ergonomic. The WRAI can control the manipulator easier than using remote control and joystick. Further, the control panel of $\mathrm{VI}$ is able to simplify the monitoring process by the friendly user interface.

Keywords: DOF, End Effetor, LabVIEW, Virtual Instrument, Wearable Robotic Arm Input.

\section{PENDAHULUAN}

Wearable robotic arm input (WRAl) merupakan pengembangan perangkat pengendalian dibidang robotika. WRAI didesain sedemikian rupa sehingga mengikuti kontur lengan manusia. Perangkatnya terdiri dari sensor-sensor yang bekerja karena respon dari getaran-getaran yang ditimbulkan dari pergerakan lengan. Hasil dari pergerakan tersebut diterima oleh lengan robot, kemudian

respon yang diberikan [1-4]. Gambar 1 menunjukan ilustrasi pengendalian lengan robot menggunakan WRAI. Pengembangan WRAl untuk pengendalian lengan robot didasarkan atas pertimbangan aspek ergonomis dan kognitif. Dari aspek ergonomis, WRAI dapat mempermudah proses pengendalian dikarenakan konstruksinya yang mengikuti kontur lengan manusia. Selain itu, dengan rancangan yang
\end{abstract} lengan robot tersebut bergerak sesuai dengan 


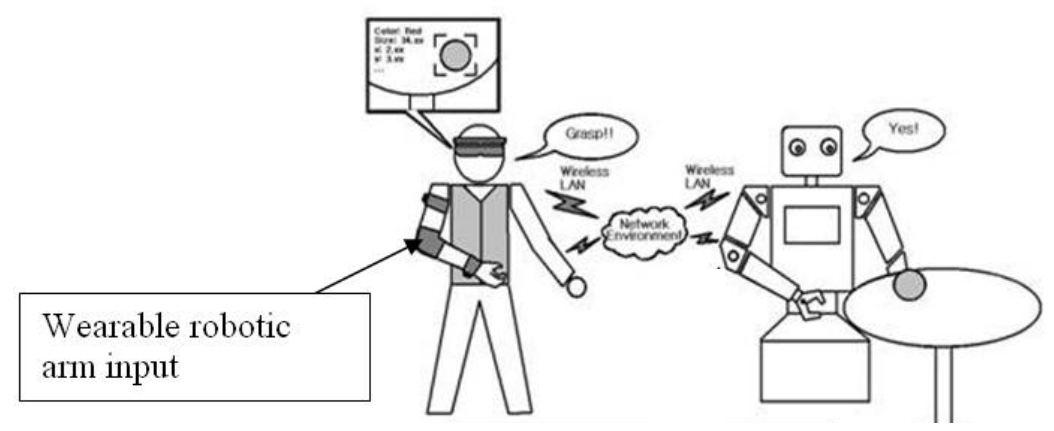

Gambar 1. Ilustrasi pengendalian lengan robot menggunakan WRAI.

sedemikian rupa, diharapkan penggunaannya dapat menjadi lebih nyaman dan aman dibandingkan dengan penggunaan remote control atau joystik. Dari aspek kognitif, penggunaan control panel virtual instrument (VI) sebagai user interface diharapkan dapat membantu penggunanya dalam memantau lengan robot secara terukur, dan dapat mengurangi kelelahan pikiran dibandingkan pemantauan secara langsung [5].

Dalam studi ini, kinematika lengan robot menjadi pokok bahasan utama. Secara garis besar, masalah kinematika dapat dibedakan menjadi dua yaitu forward kinematics dan inverse kinematics [1,6]. Forward kinematics membahas tentang perhitungan posisi dan orientasi lengan robot yang bergerak relatif terhadap suatu titik referensi. Sedangkan inverse kinematics membahas tentang perhitungan besarnya sudut yang dibentuk oleh joint pada posisi tertentu. Terdapat tiga langkah dalam memodelkan forward kinematics, diantaranya adalah penentuan arah sumbu koordinat $x, y$, dan $z$ pada masing-masing joint, penentuan Denavit-Hartenberg (D-H) parameter, dan perhitungan matrix transformasi. Arah sumbu koordinat $x, y$, dan $z$ pada masing-masing joint dapat ditentukan dengan menggunakan kaidah tangan kanan, dimana jari jempol menunjukkan arah dari koordinat $x$, jari telunjuk menunjukkan arah koordinat $y$, dan jari tengah menunjukkan arah koordinat $z$. Arah koordinat yang pertama harus ditentukan adalah arah koordinat $z$, dimana arah koordinat $z$ searah dengan sumbu joint.
Pada penggunaan revolute joint, $\theta_{i}$ pada $\mathrm{D}-\mathrm{H}$ parameter adalah sudut joint yang terbentuk pada saat pergerakan lengan robot, sedangkan $\alpha_{i}$, $a_{i}$, dan $d_{i}$ merupakan dimensi dari lengan robot $[1,6]$. Penjelasan mengenai $\mathrm{D}-\mathrm{H}$ parameter pada lengan robot dapat dilihat pada gambar 2, dimana $i$ adalah link ke $i, i-1$ adalah link ke $i-1, \alpha_{i}$ adalah sudut antara $z_{i}$ dan $z_{i+1}$ pada sumbu $x_{i}, a_{i}$ adalah jarak antara $z_{i i}$ dan $z_{i+1}$ diukur sepanjang $x_{i}, \theta_{i}$ adalah sudut antara $x_{i-1}$ dan $x_{i}$ pada sumbu $z_{i}$, dan $d_{i}$ adalah jarak antara $x_{i-1}$ dan $x_{i}$ diukur sepanjang $z_{i}$.

Perhitungan matrix tranformasi dapat dilakukan setelah D-H parameter pada joint lengan robot telah ditentukan.

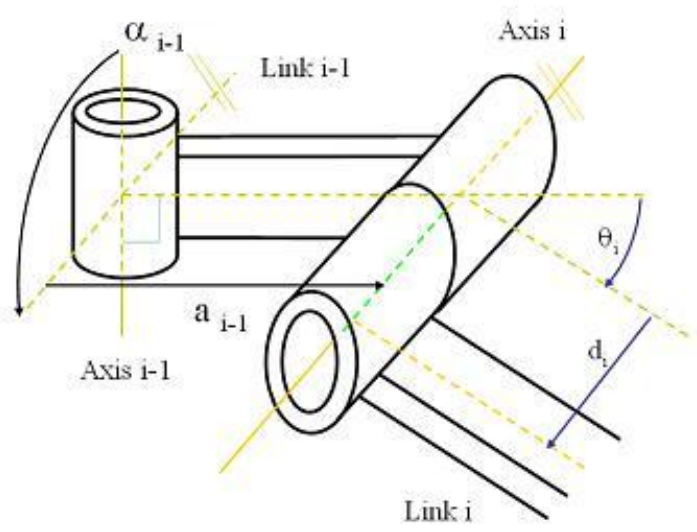

Gambar 2. Penentuan D-H parameter pada revolute joint [1].

Tujuan pembentukan matrix transformasi adalah untuk menunjukkan posisi dan orientasi joint-i bergerak relatif terhadap join-i-1. Gambar 2 memperlihatkan link- $i$ bergerak relatif 
terhadap link-i-1. Link berotasi pada sumbu $x_{i-1}$ sehingga terbentuk sudut $a_{i-1}$, lalu link bertranslasi sepanjang sumbu $x_{i-1}$ sejauh $a_{i-1}$. Selanjutnya link berotasi pada sumbu $z_{i}$ sehingga terbentuk sudut $\theta_{i}$, dan bertranslasi sepanjang sumbu $z_{i}$ sejauh $d_{i}$. Sehingga matrix transformasi dapat dirumuskan seperti pada Persamaan 1.

$$
{ }_{i}^{i-1} T=R_{X}\left(\alpha_{i-1}\right) \cdot D_{X}\left(a_{i-1}\right) \cdot R_{Z}\left(\theta_{i}\right) \cdot D_{Z}\left(d_{i}\right)
$$

$$
\begin{aligned}
{ }_{i}^{i-1} T & =\left[\begin{array}{cccc}
c \theta_{i} & -s \theta_{i} & 0 & a_{i-1} \\
s \theta_{i} c \alpha_{i-1} & c \theta_{i} c \alpha_{i-1} & -s \alpha_{i-1} & -s \alpha_{i-1} d_{i} \\
s \theta_{i} s \alpha_{i-1} & c \theta_{i} s \alpha_{i-1} & c \alpha_{i-1} & c \alpha_{i-1} d_{i} \\
0 & 0 & 0 & 1
\end{array}\right] \\
& =\left[\begin{array}{cccc}
r_{x x} & r_{x y} & r_{x z} & p_{x} \\
r_{y x} & r_{y y} & r_{y z} & p_{y} \\
r_{z x} & r_{z y} & r_{z z} & p_{z} \\
0 & 0 & 0 & 1
\end{array}\right]
\end{aligned}
$$

dimana:

$r$ = Elemen orientasi dalam matrix $3 \times 3$

$P=$ Elemen posisi dalam matrix $3 \times 3$.

Pembentukan matrix transformasi di atas terdapat dua informasi penting, diantaranya adalah informasi mengenai posisi joint-i yang bergerak relatif terhadap joint- $-1-1$, dan informasi mengenai orientasi yang berupa matrix $3 \times 3$ pada tiga kolom pertama.
Pada studi ini, lengan robot dikendalikan melalui WRAI, dan proses pemantauan dilakukan melalui control panel VI yang diprogram menggunakan software LabVIEW [78]. Aspek ergonomis dan kognitif menjadi bahan pertimbangan utama dalam studi kali ini.

\section{METODOLOGI PENELITIAN}

Gambar 3 menunjukan lengan robot yang tersusun oleh beberapa komponen, diantaranya adalah lima buah revolute joint yang masing-masingnya digerakkan oleh aktuator berupa motor servo, penghubung antara joint (link) yang terbuat dari aluminium, dan sebuah gripper yang terletak pada end effector. Pada kelima buah motor servo tersebut terhubung pada receiver sebagai penerima sinyal yang dikirimkan oleh transmitter pada WRAI. Sedangkan WRAI tersusun atas lima buah sensor perpindahan yaitu potensiometer yang terintegrasi langsung dengan control pane/ VI. Sensor potensiometer yang terpasang pada WRAI mengatur besarnya tegangan, kemudian dikirimkan menuju transmitter. Tegangan output yang dikirimkan oleh sensor potensiometer kemudian dirubah oleh transmitter kedalam bentuk sinyal untuk kemudian dikirim menuju receiver. Pengaturan tegangan oleh sensor potensiometer akibat pergerakan WRAI akan mempengaruhi besarnya sinyal yang akan diterima oleh receiver. Sensor potensiometer yang digunakan merupakan sensor standar yang dapat dengan mudah diperoleh di pasaran. Receiver dan transmitter yang digunakan berasal dari remote control FM radio control futaba 6EXA-6 channel seperti yang terlihat pada Gambar 4. 


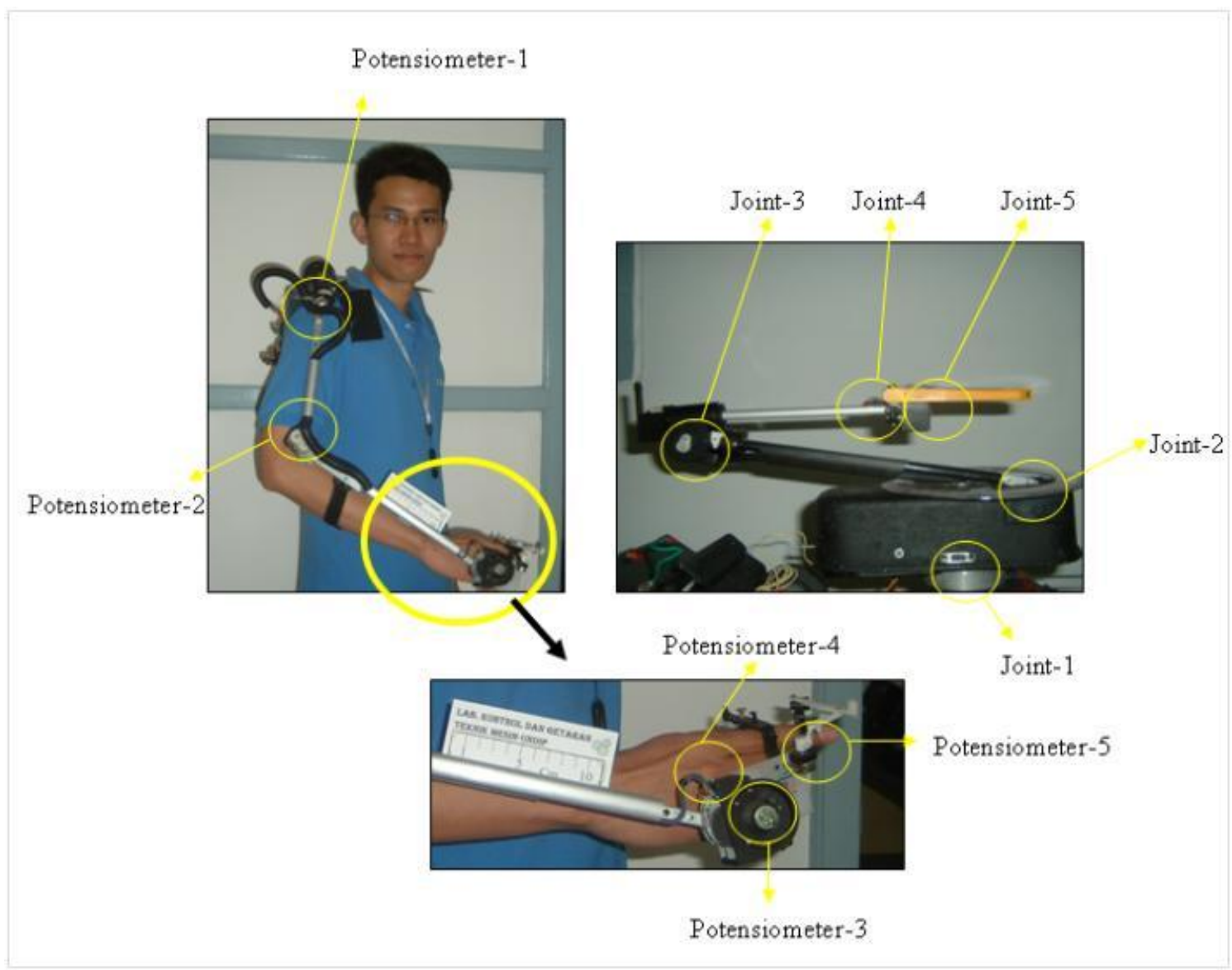

Gambar 3. Peletakan sensor potensiometer di WRAI dan aktuator pada joint di lengan robot.

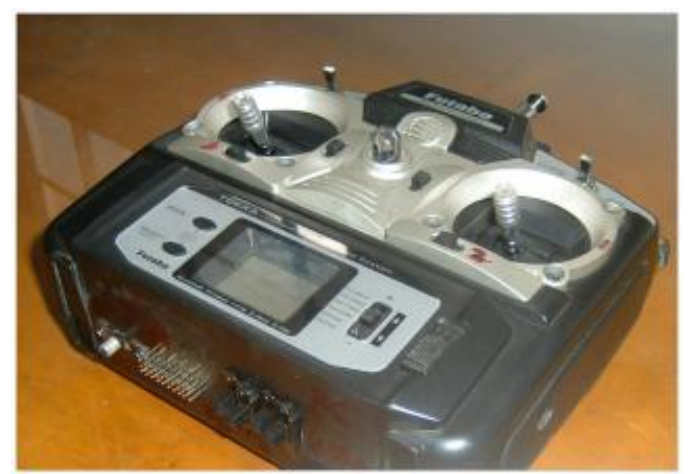

Gambar 4. Remote control FM radio control futaba 6 EXA- 6 channel.

Dengan mempertimbangkan kemudahan pengguna dalam mengendalikan lengan robot, maka peletakan sensor pada WRAI disesuaikan dengan peletakan aktuator pada lengan robot. Urutan peletakan sensor dimulai dari bagian pangkal lengan dan berakhir pada ujung jari telunjuk. Peletakan joint pada lengan robot dimulai dari bagian base dan berakhir pada bagian end effector. Gambar 5 menunjukkan alur metodologi yang digunakan dalam proses pengendalian dan pemantauan lengan robot.

\section{HASIL DAN PEMBAHASAN Identifikasi sensor}

Sebelum dioperasikan, maka pada masing-masing sensor dilakukan pengidentifikasian agar diketahui karakteristik sensor secara nyata. Pengidentifikasian dilakukan untuk mengetahui karakteristik sensor sesuai lingkungan yang akan 
digunakan, agar bekerja dengan optimal. potensiometer yang digunakan pada WRAI Gambar 6 menunjukan hasil identifikasi sensor memiliki spesifikasi yang sama, memiliki nilai potensiometer berupa grafik pengaruh hambatan sebesar $5 \mathrm{~K} \Omega$, dan sudut yang perubahan tegangan terhadap besarnya sudut terbentuk saat memutar potensiometer putaran yang terbentuk. Masing-masing maksimum sebesar $295^{\circ}$,

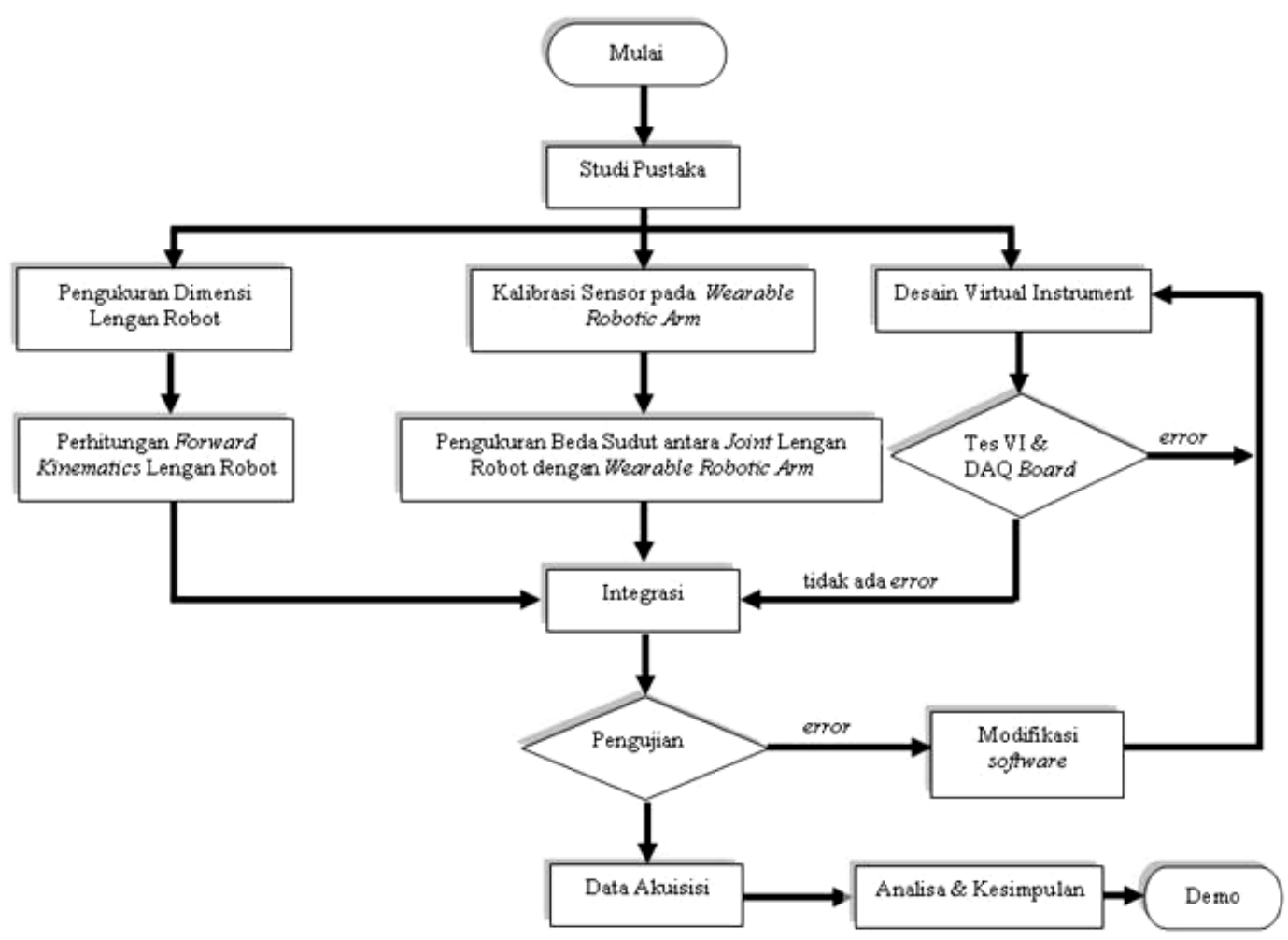

Gambar 5. Diagram alur pengembangan WRAI dan VI untuk pengendalian lengan robot.

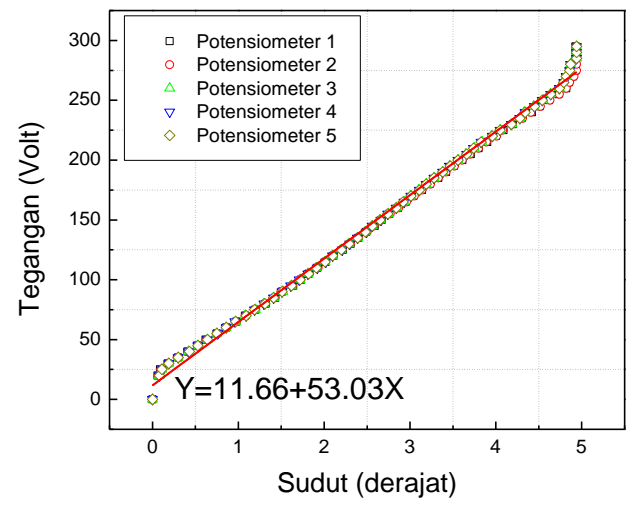

Gambar 6. Grafik hubungan antara tegangan terhadap sudut putaran yang dibentuk oleh potensiometer.

Kurva yang terbentuk pada masingmasing potensiometer saling berimpit antara yang satu dengan yang lainya. Dengan perolehan data tersebut dapat ditarik kesimpulan bahwa masing-masing potensiometer memiliki karakteristik yang sama sesuai dengan identifikasi yang dilakukan, yaitu karakteristik yang linear. Dari kurva yang terbentuk diperoleh persamaan linear seperti pada Persamaan 2.

$Y=11.66+53.03 X$ 
Hasil pengukuran perubahan tegangan terhadap sudut yang terbentuk pada motor servo tidak ditampilkan dalam artikel ini karena sudah diperoleh dari data sheet.

\section{Analisis Forward Kinematics}

Pemodelan gerakan lengan robot dapat

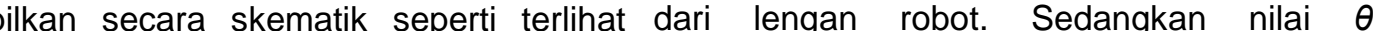
pada Gambar 7. Pemodelan ini dilakukan untuk berdasarkan dari perubahan sudut yang memperlihatkan arah gerak masing-masing link terbentuk pada sensor potensiometer pada dan posisi kedudukan antar joint yang satu saat digerakkan.

dengan yang lainnya baik berupa posisi sejajar atau berpotongan.

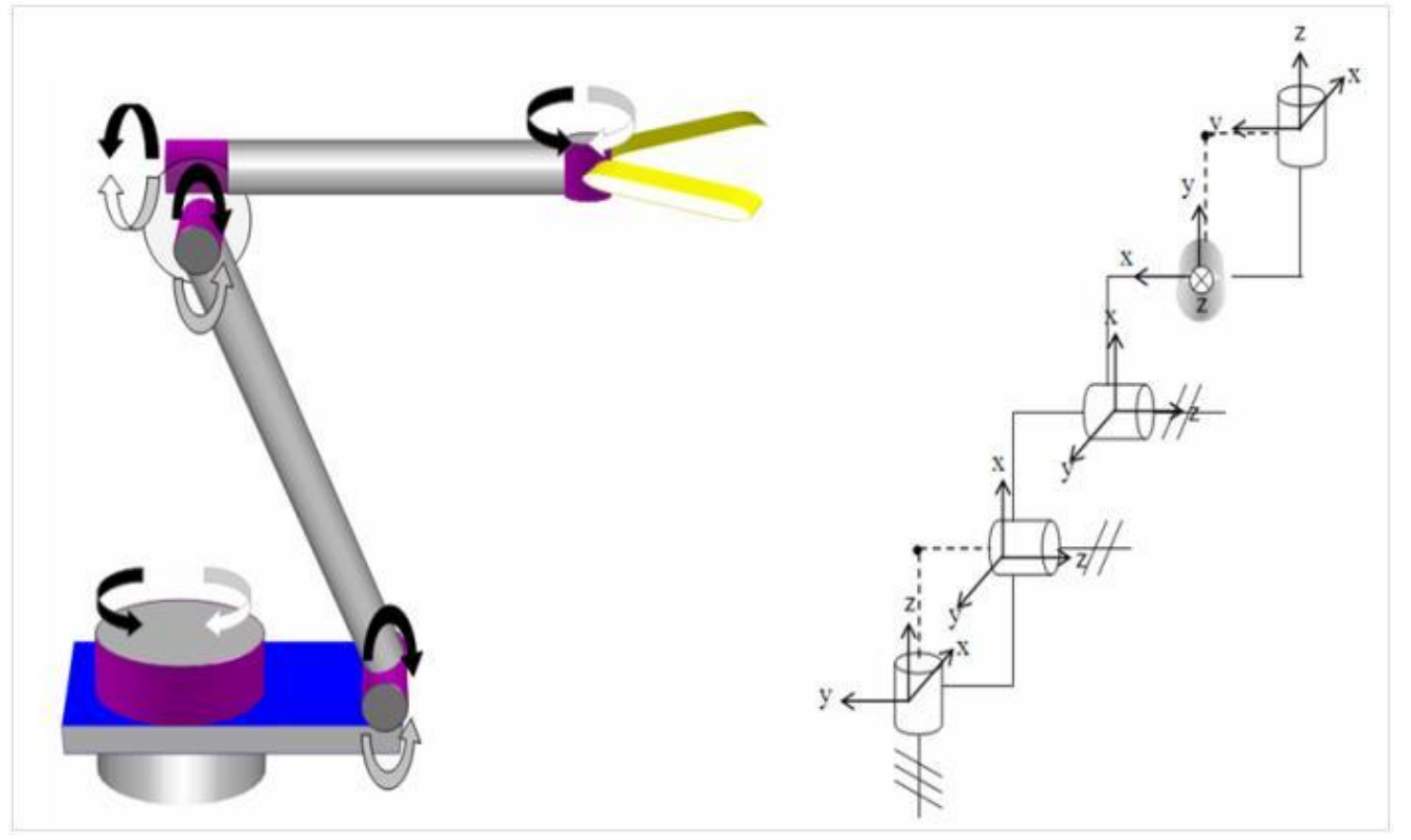

Gambar 7. Penentuan sumbu koordinat pada masing-masing joint. 


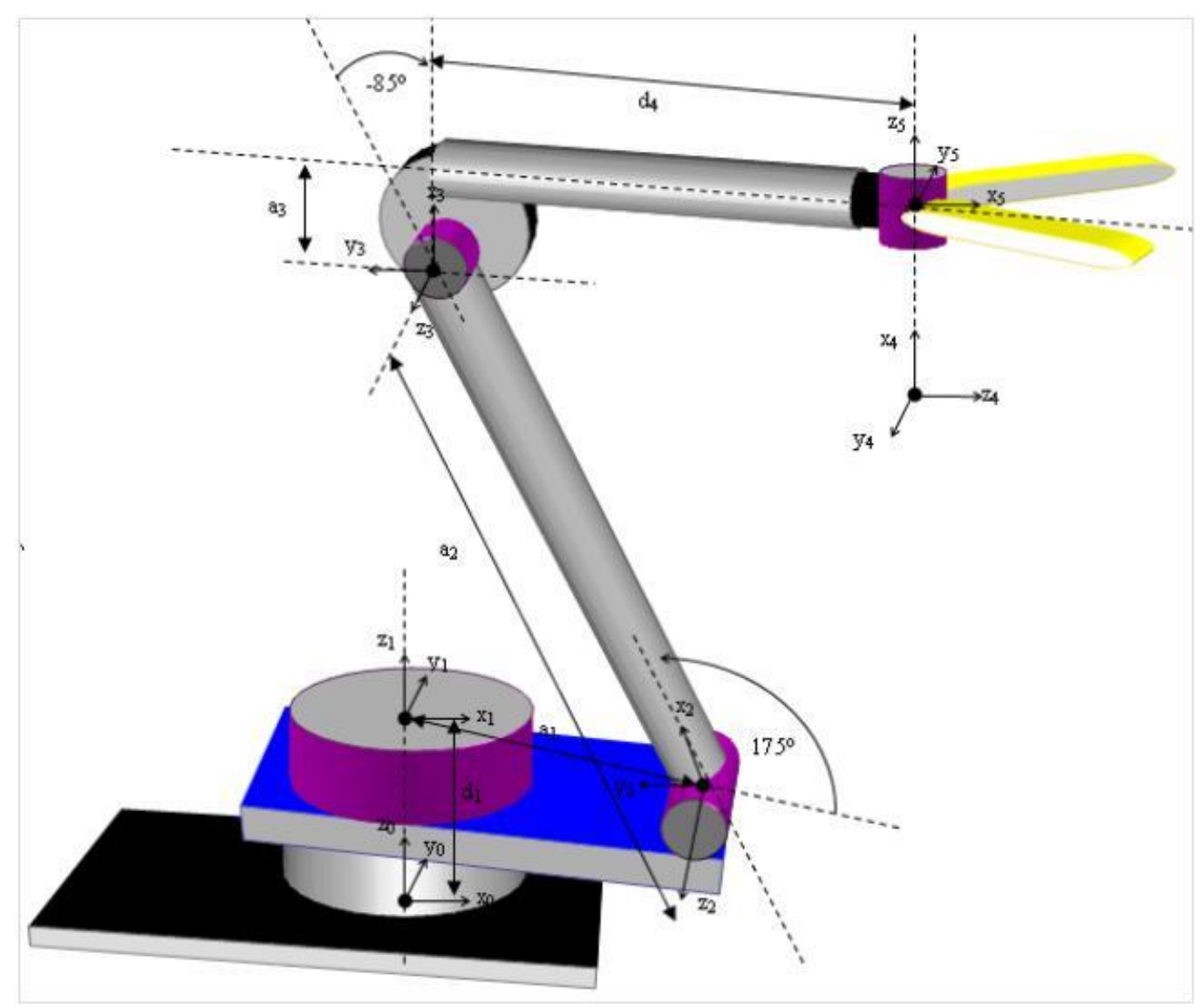

Gambar 8. D-H parameter pada saat posisi setting nol lengan robot.

Tabel 1. D-H parameter pada lengan robot.

\begin{tabular}{cccc}
\hline $\mathbf{i}$ & $\left.\boldsymbol{\alpha}_{\mathrm{i}-\mathbf{1}} \mathbf{(}^{\mathbf{0}}\right)$ & $\mathbf{a}_{\mathbf{i}-\mathbf{1}}(\mathbf{c m})$ & $\mathbf{d}_{\mathbf{i}}(\mathbf{c m})$ \\
\hline 1 & 0 & 0 & 6 \\
\hline 2 & 90 & 6 & 0 \\
\hline 3 & 0 & 26.5 & 0 \\
\hline 4 & 90 & 2 & 18 \\
\hline 5 & -90 & 0 & 0 \\
\hline
\end{tabular}

$$
{ }_{i}^{i-1} T=\left[\begin{array}{cccc}
c \theta_{i} & -s \theta_{i} & 0 & a_{i-1} \\
s \theta_{i} c \alpha_{i-1} & c \theta_{i} c \alpha_{i-1} & -s \alpha_{i-1} & -s \alpha_{i-1} d_{i} \\
s \theta_{i} s \alpha_{i-1} & c \theta_{i} s \alpha_{i-1} & c \alpha_{i-1} & c \alpha_{i-1} d_{i} \\
0 & 0 & 0 & 1
\end{array}\right]_{(3) .}
$$

Untuk penyederhanaan tampilan, maka pada matrix transformasi menggunakan simbol $c$ untuk mewakili $\cos$, dan $s$ untuk mewakili sin.

Transformasi matrix link 1 terhadap link 0

Setelah D-H parameter diperoleh, maka tahap berikutnya adalah melakukan perhitungan matrix transformasi. Tujuan akhir matrix transformasi adalah untuk menentukan posisi dan orientasi posisi ujung lengan robot (end effector) bergerak relatif terhadap joint 1

$$
{ }_{1}^{0} T=\left[\begin{array}{cccc}
c \theta_{1} & -s \theta_{1} & 0 & 0 \\
s \theta_{1} & c \theta_{1} & 0 & 0 \\
0 & 0 & 1 & d_{1} \\
0 & 0 & 0 & 1
\end{array}\right]
$$


Transformasi matrix link 2 terhadap link 1

${ }_{2}^{1} T=\left[\begin{array}{cccc}c \theta_{2} & -s \theta_{2} & 0 & a_{1} \\ 0 & 0 & -1 & 0 \\ s \theta_{2} & c \theta_{2} & 0 & 0 \\ 0 & 0 & 0 & 1\end{array}\right]$

${ }_{5}^{3} T={ }_{4}^{3} T_{5}^{4} T=\left[\begin{array}{cccc}c_{4} c_{5} & -c_{4} s_{5} & -s_{4} & a_{3} \\ s_{5} & c_{5} & 0 & -d_{4} \\ s_{4} c_{5} & -s_{4} s_{5} & c_{4} & 0 \\ 0 & 0 & 0 & 1\end{array}\right]$

(5),

Transformasi matrix link 3 terhadap link 2

${ }_{3}^{2} T=\left[\begin{array}{cccc}c \theta_{3} & -s \theta_{3} & 0 & a_{2} \\ s \theta_{3} & c \theta_{3} & 0 & 0 \\ 0 & 0 & 1 & 0 \\ 0 & 0 & 0 & 1\end{array}\right]$

Transformasi matrix link 5 terhadap link 2

$$
{ }_{5}^{2} T={ }_{3}^{2} T_{5}^{3} T=\left[\begin{array}{cc}
c_{3} c_{4} c_{5}-s_{3} s_{5} & -c_{3} c_{4} s_{5}-s_{3} s_{5} \\
s_{3} c_{4} c_{5}+c_{3} s_{5} & -s_{3} c_{4} s_{5}+c_{3} c_{5} \\
s_{4} c_{5} & -s_{4} s_{5} \\
0 & 0
\end{array}\right.
$$

(6),

Transformasi matrix link 4 terhadap link 3

${ }_{4}^{3} T=\left[\begin{array}{cccc}c \theta_{4} & -s \theta_{4} & 0 & a_{3} \\ 0 & 0 & -1 & -d_{4} \\ s \theta_{4} & c \theta_{4} & 0 & 0 \\ 0 & 0 & 0 & 1\end{array}\right]$

$$
\begin{array}{cc}
-c_{3} s_{4} & c_{3} a_{3}+s_{3} d_{4}+a_{2} \\
-s_{3} s_{4} & s_{3} a_{3}-c_{3} d_{4} \\
C_{4} & 0
\end{array}
$$

Transformasi matrix link 5 terhadap link 4

$$
{ }_{5}^{4} T=\left[\begin{array}{cccc}
c \theta_{5} & -s \theta_{5} & 0 & 0 \\
0 & 0 & 1 & 0 \\
-s \theta_{5} & -c \theta_{5} & 0 & 0 \\
0 & 0 & 0 & 1
\end{array}\right]
$$

(8).

Transformasi matrix link 2 terhadap link 0

$$
{ }_{2}^{0} T={ }_{1}^{0} T_{2}^{1} T=\left[\begin{array}{cccc}
c_{1} c_{2} & -c_{1} s_{2} & s_{1} & a_{1} c_{1} \\
s_{1} c_{2} & -s_{1} s_{2} & -c_{1} & a_{1} s_{1} \\
s_{2} & c_{2} & 0 & d_{1} \\
0 & 0 & 0 & 1
\end{array}\right]
$$

Transformasi matrix link 5 terhadap link 0

Untuk memperoleh matrix transformasi link 5 terhadap link 0 , dilakukan dengan mengalikan matrix transformasi antar link seperti terlihat di bawah ini. Untuk selanjutnya, penggunaan simbol $c$ kembali digunakan untuk penyederhanaan $\cos \theta$ dan $s$ untuk $\sin \theta$.

$$
{ }_{5}^{0} T={ }_{2}^{0} T_{5}^{2} T=\left[\begin{array}{cccc}
r_{x x} & r_{x y} & r_{x z} & p_{x} \\
r_{y x} & r_{y y} & r_{y z} & p_{y} \\
r_{z x} & r_{z y} & r_{z z} & p_{z} \\
0 & 0 & 0 & 1
\end{array}\right]
$$

Transformasi matrix link 5 terhadap link 3

Dimana $r$ merepresentasikan orientasi, yaitu berupa matrix $3 \times 3$, dan $p$ merepresentasikan posisi end effector terhadap acuan joint 1. Nilai $r$ dan $p$ dapat dilihat pada perhitungan di bawah ini. Khusus untuk 
orientasi lengan robot, pada control pane/ VI hanya akan diwakilkan oleh tiga buah elemen dari matix $3 \times 3$, diantaranya $r_{x x}, r_{y y}$, dan $r_{z z}$. Hal ini dilakukan untuk penyederhanaan tampilan pemantauan orientasi pada control pane/ VI.

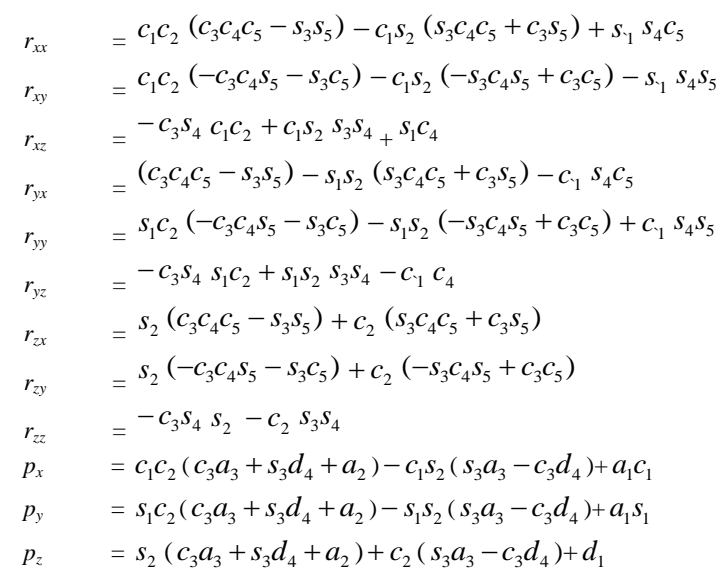

\section{Pemrograman control panel VI}

Control panel VI digunakan untuk memantau posisi dan orientasi end effector terhadap titik acuan joint 1 . Selain itu, beberapa program pengendalian ditambahkan untuk melakukan pengendalian lengan robot pada control panel VI. Lima buah sinyal tegangan yang berasal dari sensor potensiometer yang terdapat di WRAI dihubungkan pada control panel VI melalui DAQPad-6020E [9-11]. Dari kelima buah sinyal yang telah diolah, dua diantaranya dikeluarkan melalui analog output channel dan satu sisanya dikeluarkan melalui digital output channel. Sinyal yang dikeluarkan melalui digital output merupakan sinyal yang telah diolah di dalam VI yang berfungsi untuk mengendalikan end effector melalui panel digital. Sedangkan dua sinyal yang dikeluarkan melalui analog output channel berfungsi untuk mengendalilkan lengan robot pada bagian joint2 dan 3. Lengan robot tersebut dikendalikan dengan cara mengontrol sinyal pada WRAl. Pengontrolan sinyal tersebut dilakukan dengan mengatur sinyal agar menjadi konstan sesuai dengan besarnya sinyal yang diinginkan oleh pengguna. Kemudian sinyal yang bernilai konstan tersebut dikirim menuju lengan robot. Dengan teknik pengontrolan ini lengan robot akan berada pada posisi tetap walaupun sensor pada WRAI mengalami perubahan sudut. Tujuan dari pengendalian ini adalah agar joint2 dan 3 pada lengan robot dapat dihentikan pergerakannya pada posisi yang diinginkan dan tidak terpengaruh gerakan dari joint lainnya. Konstruksi WRAI yang masih sedikit kaku, mengakibatkan pergerakan potensiometer yang satu masih dapat mempengaruhi gerakan potensiometer yang lainnya, terutama pada bagian joint-2 dan 3. Gambar 9 dan 10 menunjukan keseluruhan tampilan control panel VI beserta block diagram untuk pengendalian lengan robot. Pada tampilan control panel VI beberapa penjelasan dijabarkan di bawan ini.

1. Angle of joints

Dari panel ini, pengguna dapat mengetahui besarnya sudut yang terbentuk pada masing-masing joint ketika lengan robot digerakkan.

\section{Lock/ unlock joint $2 \& 3$}

Ini merupakan panel yang digunakan untuk mengendalikan dua buah sinyal pada WRAI agar nilainya dapat berubah atau dapat dibuat konstan selama proses pengendalian. 


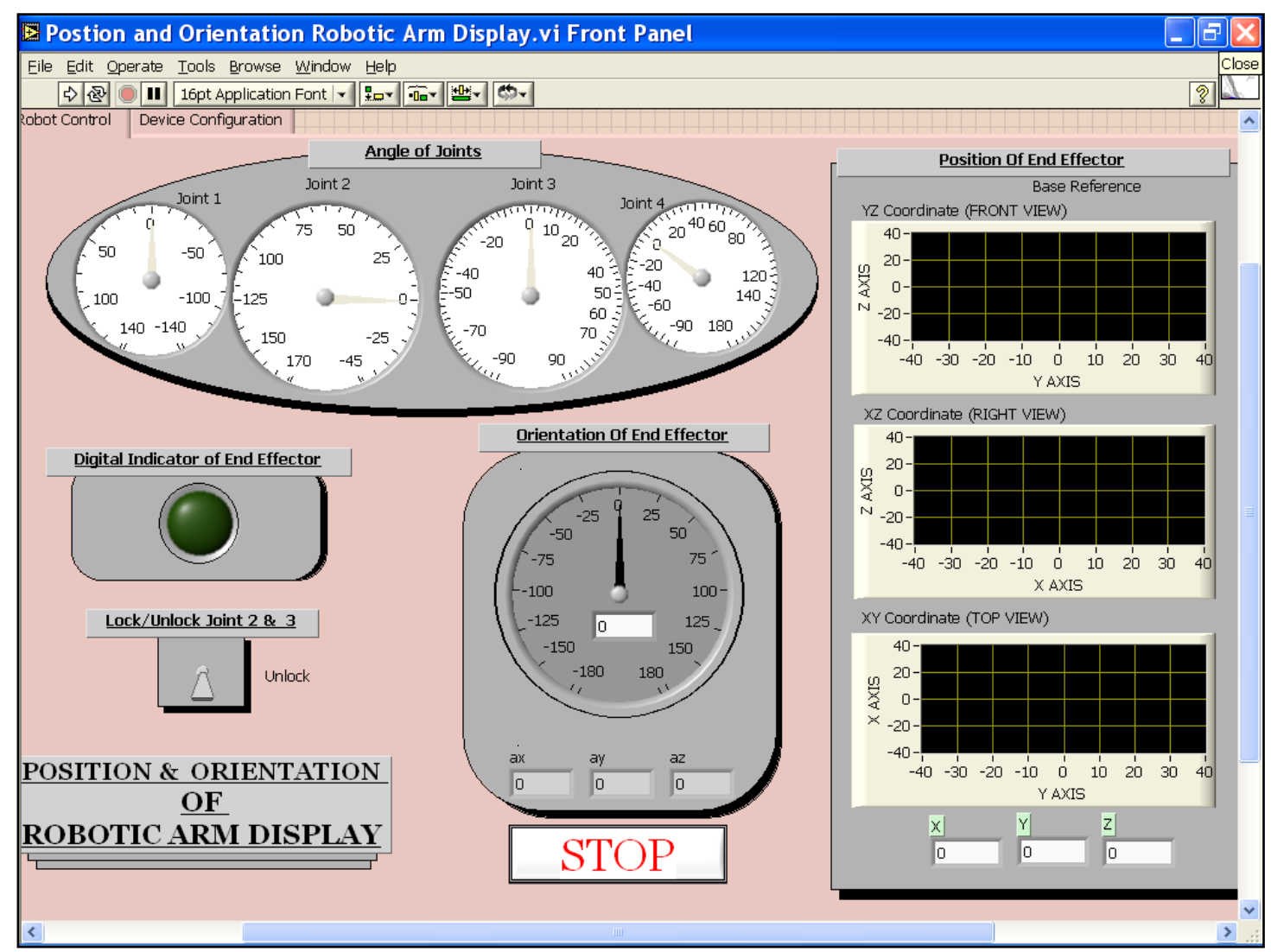

Gambar 9. Control panel pada VI untuk pemantauan dan pengendalian lengan robot.

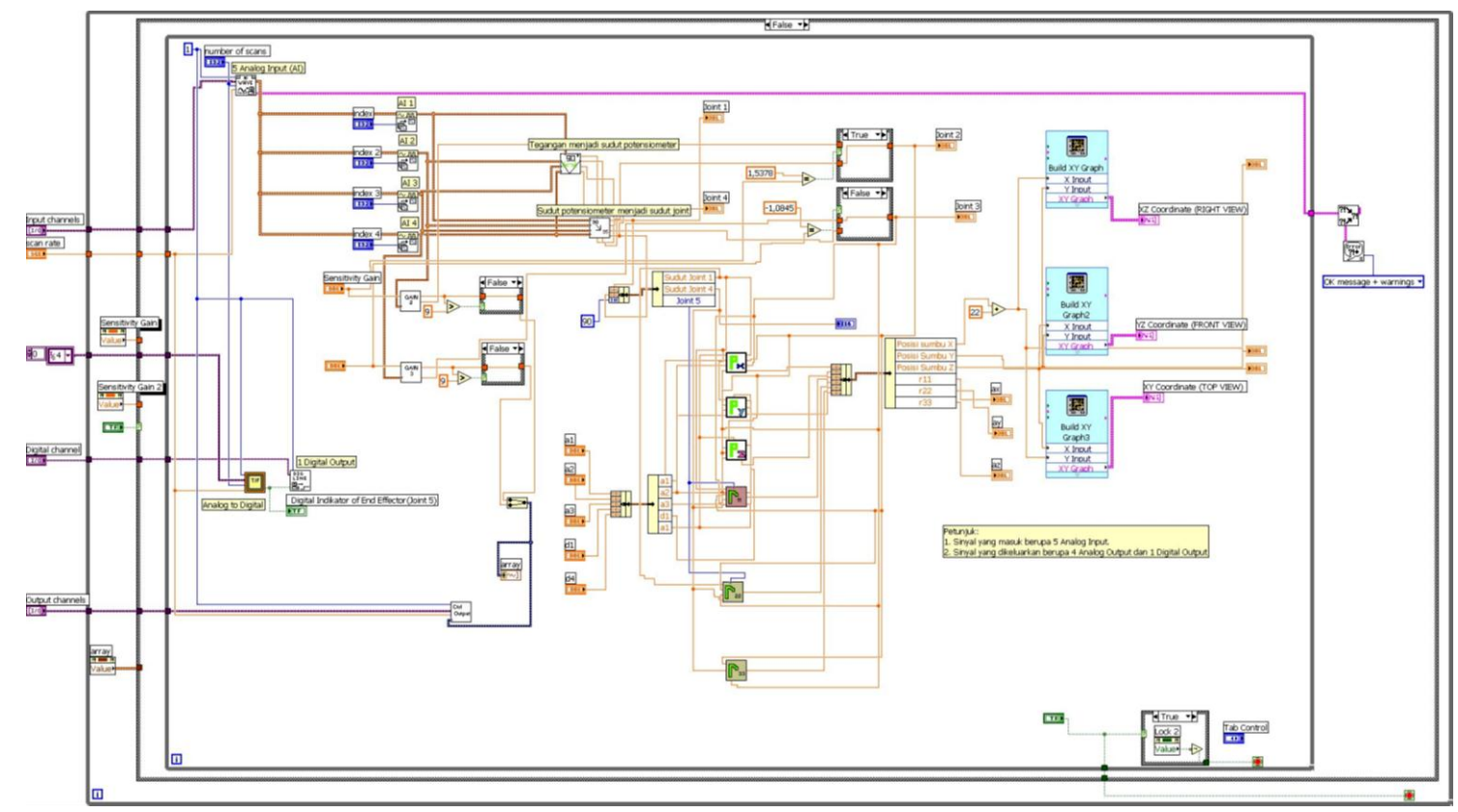

Gambar 10. Block diagram pada VI untuk pemantauan dan pengendalian lengan robot. 
3. Digital indicator of end effector

Panel indikator ini digunakan untuk mengetahui kondisi end effector dalam keadaan menggenggam atau tidak menggenggam. Apabila indikator menyala, maka end effector sedang berada dalam kondisi menggenggam. Dan sebaliknya apabila indikator tidak menyala, maka end effector sedang dalam kondisi bebas/ tidak menggenggam.

4. Position of end effector

Pada panel ini pengguna dapat memantau posisi relatif end effector terhadap acuan joint 1. Pada panel ini terdapat tiga buah titik pandangan, diantaranya adalah pandangan atas (top view), depan (front view), dan kanan (right view). Dengan ketiga buah view tersebut diharapkan dapat merepresentasikan posisi lengan robot secara keseluruhan.

5. Orientation of end effector

Panel ini berfungsi untuk memantau orientasi end effector bergerak relatif terhadap acuan joint 1 .

\section{KESIMPULAN}

Dari hasil pengendalian dan pemantauan lengan robot menggunakan WRAl yang terintegrasi dengan control pane/ $\mathrm{VI}$, diperoleh hasil sebagai berikut:

1. Pengendalian lengan robot menggunakan WRAI hampir sebagian besar memenuhi aspek ergonomis. Desain yang mengikuti kontur lengan manusia dan pergerakan yang menyerupai lengan manusia memudahkan untuk melakukan pengendalian secara aman dan nyaman.

2. Pengendalian menggunakan WRAI masih dirasa sedikit kurang sempurna, karena desain yang masih sedikit kaku akibat keterbatasan materialnya.

3. Penggunaan control panel VI sebagai alat pemantau dan juga pengendalian, sudah dapat memenuhi aspek kognitif, dimana pengguna dapat memantau posisi dan orientasi end effector secara lebih terukur dan mengurangi kelelahan pikiran selama pemantauan.

\section{DAFTAR PUSTAKA}

[1] Angeles, J., 2003, "Fundamentals of Robotic Mechanical Systems: Theory, Methods, and Algorithms," Springer-Verlag, New York.

[2] Bolton, W., 1999, "Mechatronics: Electronics Control Systems in Mechanical Engineering", Addison Wesley Longman, USA.

[3] Bräunl, T, 2006, "Embedded Robotics: Mobile Robot Design and Applications with Embedded Systems", Springer-Verlag, Berlin Heidelberg.

[4] Craig, J., J., 1955, "Introduction to Robotics, Mechanics and Control", Addison-Wesley Inc., New York.

[5] Cooke, N., J., Pringle, Heather I, Pedersen H. K., and Connor,. O., 2006," Advances in Human Performance and Cognitive Engineering Research Volume 7: Human Factors of Remotely Operated Vehicles", Elsevier Ltd.

[6] Meriam, J. L, 1987, "Engineering Mechanics, Dynamics, Volume 2", John Wiley \& Sons, Inc., New York.

[7] LabVIEW, 1998, "Data Acquisition Basics Manual', National Instruments Corporation, Texas.

[8] LabVIEW 7, 2003, "Express Measurement Manual', National Instruments Corporation, Texas.

[9] Pires, J., Norberto, 2007, "Industrial Robots Programming: Building Applications for the Factories of the Future", Springer Science and Business Media, LLC.

[10] Shircliff, David, R., 2002, "Build A RemoteControlled Robot", The McGraw Hill Companies, Inc.

[11] Smith, Steven, W., 2006, "The Scientist and Engineer's Guide to Digital Signal Processing", California Technical Publishing. 